\title{
Early Design Tool For PV + Battery Sizing: An Approach To Maximize The Economic Outlook Of BIPV By Increasing Self-Consumption
}

\author{
Mattia Dallapiccola ${ }^{1}$, Marco Lovati ${ }^{1,2}$, Jennifer Adami $^{1}$, David Moser ${ }^{1}$ \\ ${ }^{1}$ Eurac Research, Bolzano, Italy \\ ${ }^{2}$ Università degli Studi di Trento
}

\begin{abstract}
This paper analyzes some possible approaches that can be adopted to design and size a residential building integrated $P V+E E S$ (Photovoltaic + Electrical Energy Storage) system in the early design phases. A set of "basic" approaches based on cumulative values, which cannot estimate a relation between system capacity and self-consumption percentage, is typically used by designers. Besides, a design process aided by the use of a future novel version of the tool ProCasaClima is presented. This is characterized by a real-time hourly energy balance between the system production and the building consumption. The benefits of the proposed design are shown on the economic and energy indexes and compared with the results of commonly used sizing methods.
\end{abstract}

\section{Introduction}

During the early stage of the architectural design workflow of a building with $P V$, designers need design methods for sizing and positioning of $P V$ and batteries to ensure a good level of performance in the operational phase. Different methods can be used depending on the main goal to achieve. In (Freitas, Reinhart, \& Brito, 2018) and (Waibel, Mavromatidis, Bollinger, Evins, \& Carmeliet, 2018) the authors optimize the PV plant according to different KPIS (Key Performance Indicators). In (Lovati, et al., 2018) the authors show the possibility of using the $N P V$ (Net Present Value) as a good indicator to size and design a BIPV system. Nevertheless, if the hourly energy balance of the building $+P V$ is not taken into account, the $N P V$ calculation of the $P V$ system is not connected to the relation between self-consumption and capacity of the system (i.e. the increase, for larger systems, of the energy that is not contemporarily consumed and is therefore fed into the grid). When the hourly balance is not considered, regardless of the accuracy of the $P V$ simulation, it is not possible to establish an $N P V$ oriented design criterion. In fact, even if a non- $100 \%$ self-consumption percentage is considered, this value is constant with varying $P V$ capacity as the relation between capacity and over-production cannot be clearly estimated. The alternatives commonly used by designers are generally based on a target capacity or on a target cumulative production (e.g. have a cumulative $P V$ production equal to the cumulative demand). The new version of the tool ProCasaClima, was used to compare different sizing methods in terms of their economic performance. With respect to the previous versions, the new tool relies on an hourly energy balance and can therefore be used to implement a sizing method similar to (Lovati, et al., 2018). In (Lovati, et al., 2018) the method is presented and the positive impact on the design decision is evaluated, but what happens if the designer does not have an accurate hourly demand to use as an input? Is the method still an improvement if only the cumulative load is known and is assumed as a constant hourly schedule? The results show the positive impact in economic performance due to the main innovation of the updated tool. Even in absence of hourly data, using the cumulative demand as a static value (method 4 , constant electrical demand), the KPIs are improved compared with traditional methods. In fact, the possibility of calculating the hourly based $S P$ (self-production) and $S C$ (selfconsumption) coefficients for different $P V+E E S$ systems and electric demand profiles unlocks the possibility of sizing and positioning of $P V$ and batteries according to hourly data related KPIs. Through the comparison with different sizing methods it was shown why an hourly analysis is a fundamental aspect to obtain a well sized system which reduces the purchased energy maximizing the economic benefits of the investment. The KPIs analyzed in this study are the $N P V$ and the $S P$ previously introduced which have been used for comparing different design methods. Moreover, the effect of batteries was analyzed to demonstrate the impact of $S C$ and $S P$ indexes.

\section{Methods}

Different sizing methods that can be used by designers in the early design phase of a residential photovoltaic plant were compared using a case study. The analyzed building is based in Bolzano, in Northern Italy, and has a GIA (Gross Internal Area) of $354 \mathrm{~m}^{2}$. Fortyfour people live in the building where the electrical demands where obtained through LPG, LoadProfileGenerator (Pflugradt, 2019). Table 1 reports the early design methods compared in this work. Method 1 aims to respect the actual Italian directive (DECRETO LEGISLATIVO n. 28, 2011) for $P V$ installation on new buildings. The directive sets the minimum installed nominal capacity according with the following formula:

$$
\mathrm{P}_{\mathrm{n}, \min }=\mathrm{S} / \mathrm{K}
$$


where $P_{n, \min }$ expresses the minimum nominal capacity to be installed, $S$ is the $G I A$ of the building and $K$ is a coefficient equal to 50 .

Table 1: Early-design methods.

\begin{tabular}{|c|c|c|}
\hline & Method & Goal \\
\hline 1 & D.Lgs. $28 / 2011$ & $\begin{array}{l}\text { Install the minimum capacity } \\
\text { suggested by the current Italian } \\
\text { law }\end{array}$ \\
\hline 2 & $\begin{array}{c}\text { Annual } \\
\text { cumulative }\end{array}$ & $\begin{array}{l}\text { Install the PV capacity required to } \\
\text { cover the annual cumulative } \\
\text { demand }\end{array}$ \\
\hline 3 & $\begin{array}{c}\text { Monthly } \\
\text { cumulative } \\
\text { (different } \\
\text { seasons) }\end{array}$ & $\begin{array}{l}\text { Install the PV capacity required to } \\
\text { cover the electrical demand on } \\
\text { monthly basis }\end{array}$ \\
\hline 4 & $\begin{array}{c}\text { Constant } \\
\text { electrical demand }\end{array}$ & $\begin{array}{l}\text { Optimize } \text { the } P V \text { capacity } \\
\text { assuming a constant } \\
\text { load }\end{array}$ \\
\hline 5 & $\begin{array}{c}\text { Hourly electrical } \\
\text { demand }\end{array}$ & $\begin{array}{l}\text { Optimize the PV capacity using the } \\
\text { real electrical demand of the } \\
\text { building }\end{array}$ \\
\hline
\end{tabular}

The annual and monthly cumulative methods (method 2 and method 3 ) assume that the $P V$ plant is sized to cover the annual and monthly cumulative demands of the building. The cumulative values where obtained summing the hourly demand profile to have coherent values. In the monthly approach four reference months were used (see Table 2).

Table 2: Cumulative demands.

\begin{tabular}{|c|c|}
\hline Cumulative & Energy [kWh] \\
\hline Annual & 44000 \\
\hline January & 4480 \\
\hline April & 3669 \\
\hline July & 3068 \\
\hline October & 3659 \\
\hline
\end{tabular}

Method 4 uses the hourly features of ProCasaClima, but it assumes a constant electrical demand calculated dividing uniformly the annual cumulative demand. In this example the constant demand results equal to $5.02 \mathrm{~kW}$. This case evaluates the entity of the error in case an hourly demand curve is not available to the designer. The last method is based on an hourly approach and it exploits the full potential of the new version of the ProCasaClima module for $P V$ design. This approach was considered as the reference for the analysis of the other methods; indeed, the system designed with the different methods was then analyzed with hourly timestep to obtain the true indexes.

\section{Assumptions}

ProCasaClima permits to choose between different $P V$ technologies and type of integration such as flat roof, well ventilated tilted roof, façade integration, etc. (impact of the temperature effect was considered according to (Yusoff, 2016)). In this work, the assumptions are the use of monocrystalline modules installed on a $30^{\circ}$ South exposed roof located in Bolzano. Table 3 summarizes the $P V$ system properties.

Table 3: Plant assumptions.

\begin{tabular}{|c|c|}
\hline Technology & Monocrystalline \\
\hline Efficiency & $20 \%$ \\
\hline $\begin{array}{c}\text { Power temperature } \\
\text { coefficient }\end{array}$ & $-0.35 \% /{ }^{\circ} \mathrm{C}$ \\
\hline Type of installation & $\begin{array}{c}\text { Tilted roof-well } \\
\text { ventilated }\end{array}$ \\
\hline Ross coefficient & $0.02 \mathrm{~K} \mathrm{~m}^{2} / W$ \\
\hline
\end{tabular}

Net billing and fixed tariff were assumed as the tariff regimes used for the analysis. The discount rate for the $N P V$ calculation was assumed equal to $6.5 \%$ according to (Thornton, 2018). The NPV analysis was extended over 25 years and both inverters and the electrical storage have to be replaced after 10 years. No fiscal deductions were considered.

\section{Results - Net billing}

In this section the selected tariff regime is net billing and it was applied according to (ARERA, 2012). In summary, feed in electricity is valorized through the "scambio sul posto" mechanism up to a value equal to the annual demand. The surplus is valorized with a low value based on the zonal electricity price. Oversized $P V$ plants are thus clearly penalized.

\section{Italian legislative decree}

As reported in Table 1, method 1 for the sizing of the $P V$ plant is based on the formula given by the Italian legislative decree D.Lgs. 28/2011. The resulting nominal power for the analyzed building is equal to

$$
\mathrm{P}_{\mathrm{n}, \min }=\mathrm{S} / \mathrm{K}=7.08 \mathrm{kWp}
$$

The plant was then analyzed with ProCasaClima with an hourly timestep: the annual production of the plant results equal to $8695 \mathrm{kWh}$ corresponding to $19.7 \%$ of the annual cumulative demand (i.e. self-production). To evaluate if the plant is well sized, the $S C$ and $S P$ indexes were evaluated:

$\mathrm{SC}=\sum$ self-consumption $/ \sum$ production $=99.9 \%$

$\mathrm{SP}=\sum$ self-consumption $/ \sum$ consumption $=19.7 \%$

It is possible to observe that the produced energy is almost completely self-consumed (the load is often higher than the production) but, on the other hand, the self-produced energy is only $19.7 \%$. Based on these two observations it is possible to conclude that the plant is undersized with 
respect to the electrical demand of the building. In that case the $N P V$ after 25 years and the $P P$ (Payback Period) result equal to

$$
\begin{aligned}
& \mathrm{PP}=12.5 \text { years } \\
& \mathrm{NPV}=5612 €
\end{aligned}
$$

\section{Annual cumulative demand}

Method 2 is based on the annual cumulative demand of the building. In this approach the goal is to size the system to produce the same amount of energy that is annually consumed by the building (44 $000 \mathrm{kWh}$ ). The size of the system results to be $35.8 \mathrm{kWp}$. $S C$ and $S P$ results both equal to $54.5 \%$. In this case, the size of the system is more than four times the size of the one designed with the Italian legislative decree D.Lgs. 28/2011. The selfconsumed energy decreases since the production is higher but the purchased energy percentage (complementary to the $S P$ index) decreases until $45.5 \%$ of the total energy consumptions. Of course, the initial capital investment is higher but the resulting NPV confirms the better choice made in the current analysis

$$
\begin{aligned}
& \mathrm{PP}=13.9 \text { years } \\
& \mathrm{NPV}=43010 €
\end{aligned}
$$

\section{Monthly cumulative demand}

Method 3 suggests a size of the system which covers the monthly cumulative demand. It was decided to apply this approach using four reference months representative of the different seasons. A detailed analysis is given only for winter and summer reference months while results for October and April are reported in Table 4.

In the first case the system was designed to produce in January the cumulative demand of the selected month $(4480 \mathrm{kWh})$. The resulting size of the system is $93.9 \mathrm{kWp}$. This solution is not geometrically acceptable because assuming an efficiency of $20 \%$, the area needed for the plant would be bigger than the available roof area and it would be necessary to use a different configuration for the installation of the plant. Following results shows an oversizing of the system using this approach. In fact, the resulting annual production is 2.62 times the annual demand and $S C$ decreases to $19.6 \%$. Figure 1 shows that the monthly production of January covers the corresponding demand but in summer the system is largely oversized causing an increase of the sold energy. Moreover, $S P$ increases only marginally due to the noncontemporaneity of the demand and the production and the percentage of purchased energy is still high.

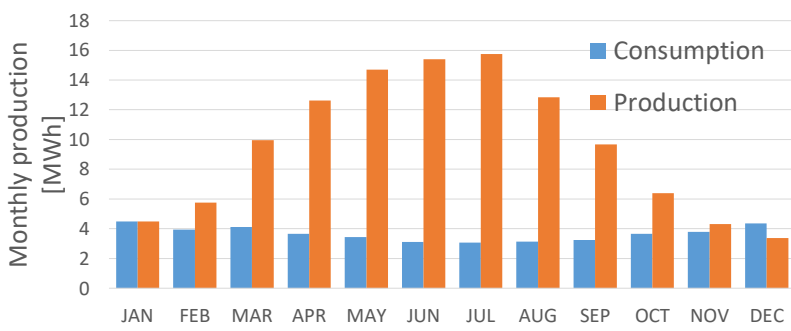

Figure 1: January consumption and production.
The economic indexes result:

$$
\begin{gathered}
\mathrm{PP}=23.0 \text { years } \\
\mathrm{NPV}=23960.4 €
\end{gathered}
$$

The $P P$ increases due to the increased initial costs of the oversized system and the low value for the valorisation of the surplus (energy fed into the grid which is not used in a later stage to cover the demand).

Considering the summer reference month, the system was designed for covering the cumulative demand of July $(3069 \mathrm{kWh})$. The resulting size of the system is $18.3 \mathrm{kWp}$. In this case the system is undersized from the energy point of view, as it is possible to notice from the following plots.

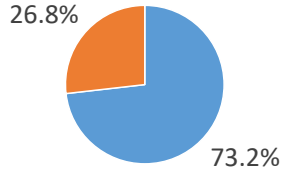

- Self consumed energy - Sold energy

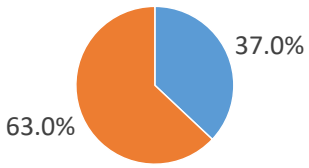

- Self produced energy

- Purchased energy
Figure 2: July cumulative - indexes.

In fact, $S C$ increases but also the percentage of purchased energy increases. Figure 3 shows that the plant matches the July consumptions while is undersized during winter mainly due to the non-optimal irradiation conditions.

In this case the results of the economic analysis are:

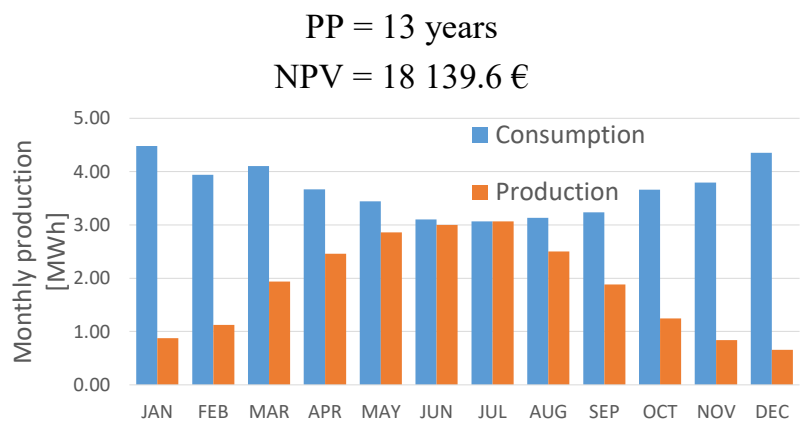

Figure 3: July consumption and production.

The same analysis was made using April and October as reference month and results obtained with the method based on the monthly cumulative demands were summarized in Table 4.

Table 4: Monthly cumulative method.

\begin{tabular}{|c|c|c|c|c|c|}
\hline Month & $\begin{array}{c}\text { Size } \\
\text { [kWp] }\end{array}$ & $\begin{array}{c}\text { SC } \\
\text { [\%] }\end{array}$ & $\begin{array}{c}\text { SP } \\
\text { [\%] }\end{array}$ & $\begin{array}{c}\text { NPV } \\
\text { [€] }\end{array}$ & $\begin{array}{c}\boldsymbol{P P} \\
\text { [years] }\end{array}$ \\
\hline January & 93.9 & 19.6 & 50.7 & 23960.4 & 23.0 \\
\hline April & 27.3 & 56.0 & 42.2 & 30612.0 & 13.4 \\
\hline July & 18.3 & 73.2 & 37.0 & 18139.6 & 13.0 \\
\hline October & 53.8 & 32.3 & 47.9 & 36782.4 & 17 \\
\hline
\end{tabular}

\section{Constant load}

Method 4 assumes that the user knows the annual cumulative demand but does not know the hourly electrical profile. Instead of covering the annual cumulative demand, the system was optimized 
maximizing the $N P V$ with the hourly tool using a constant load. The constant load can be calculated as the annual cumulative demand divided by the number of hours. In this case equal to $5.02 \mathrm{~kW}$. The resulting optimized $P V$ plant consists of $35.8 \mathrm{~kW}$ covering the $41.1 \%$ of the energy demand with the following economic outputs:

$$
\begin{gathered}
\mathrm{PP}=13.9 \text { years } \\
\mathrm{NPV}=43010.8 €
\end{gathered}
$$

\section{Hourly analysis}

Among the inputs required by the tool there is the hourly electrical profile which can be chosen from a set of electrical profiles (divided in different categories) or manually inserted. Once the load profile is defined, the user can vary the inputs (e.g. $P V$ capacity, etc.) and optimize the plant design according to their objectives (e.g. $N P V, S C, S P$, etc.), thus modifying the profiles reported for example in Figure 4. In this work it was decided to optimize the $N P V$ after 25 years.

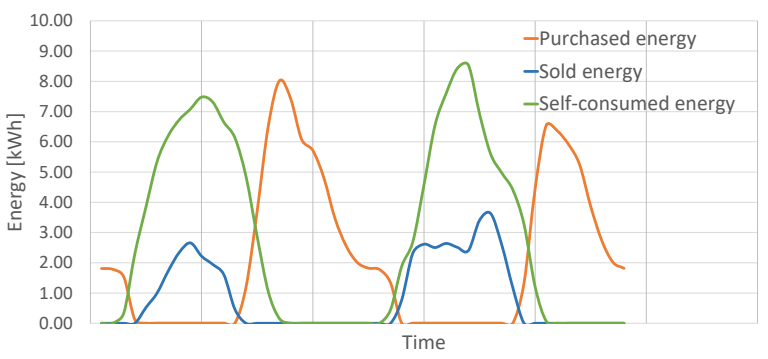

Figure 4: Consumption profiles

For the building under analysis, the optimal size of the plant results equal to $35.8 \mathrm{kWp}$. It can be observed that the optimal configuration optimized with the hourly method can be obtained also with the annual cumulative demand method and the constant load method. This is caused by the tariff regime used in the previously presented analysis and the actual costs of the components of the system. In this case, the net billing tariff decrease the importance of direct self-consumption as the feed in energy is well valorized. Thus, in this specific case, the optimal configuration can be found with different methods. The optimized economical indexes result:

$$
\begin{aligned}
& \mathrm{PP}=13.9 \text { years } \\
& \mathrm{NPV}=43011 €
\end{aligned}
$$

\section{Discussion}

Figure 5 shows the comparison between the annual purchased energy, the annual cost for electricity bills and the $N P V S$ for the different methods used for the plant design process. All design approaches lead to a consistent decrease of the purchased energy except for the Italian legislative decree and the monthly cumulative method based on July which suggest, in this case, an undersized system. It is interesting to notice that even if the reduction of the purchased energy is similar for different approaches, $N P V s$ can differ. For the analyzed case the plant designed with the Italian decree has the least $N P V$ after 25 years because it usually leads to undersized systems in case of multi-floor buildings. As discussed before, in case of net billing, the annual cumulative method and the constant electrical demand method can lead to the same results obtained with the hourly timestep optimization. However, results depend on different parameters and on the specific case of study. On the other hand, results obtained with the annual cumulative method and the constant load could lead to worse results if the price of electricity, the tariff regime, the price of inverters and photovoltaic modules change. At the same time the Italian legislative decree D.Lgs. 28/2011 can give good results compared with the hourly optimization for specific cases of study (for example single family houses). It is interesting to notice that the $N P V$ of systems designed with the Italian decree D.Lgs. 28/2011 are comparable with the ones obtained from hourly optimized systems only for a small interval of the curve shown in Figure 6. Considering the cases where few people live in the building (considering constant the GIA), the systems

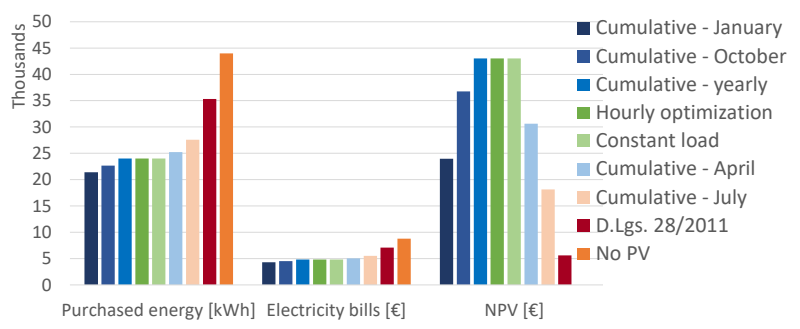

Figure 5: Methods comparison

designed with method 1 result oversized and the produced energy is not consumed. On the contrary, with the increase of the number of people living in the building (assuming the same GIA, constant number of people per floor and increasing the number of roofs) the Italian decree D.Lgs. 28/2011 tends to suggest undersized systems and consequent lower $N P V s$; this is due to the fact that the formula used in the Italian decree takes only into account the GIA. The blue line shown in Figure 6 tends to become constant because once the load is at every timestep higher than the $P V$ production and $S P$ is equal to $100 \%$, bill savings do not increase even if the load increases (the power produced by the $P V$ plant is always instantly consumed). For this reason, from a certain point on, the $N P V$ becomes almost constant at the increasing of the load.

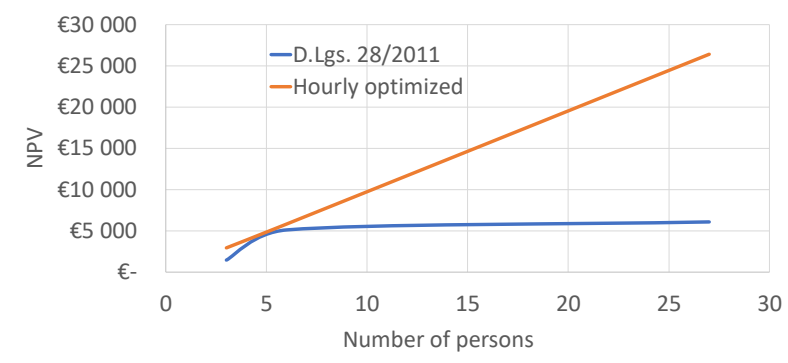

Figure 6: Number of persons - NPV

\section{Results - Fixed tariff}

The same case of study was analyzed with the methods presented in the previous paragraph but assuming a fixed tariff regime for the electricity purchased from the grid without net billing. It was assumed a price for electricity sold equal to $0.05 € / \mathrm{kWh}$ and a cost for electricity 
purchased equal to $0.2 € / \mathrm{kWh}$. For brevity, results of the different design processes were reported in Table 5. As expected, results assuming a fixed tariff regime are different with respect to the analysis assuming net billing. In fact, net billing decreases the importance of direct selfconsumption and load matching while the grid is seen as an infinite capacity electrical storage and the electricity sold to the grid is well valued. On the contrary, the fixed tariff regime (and the same for more complex tariffs) penalizes the oversized systems (bad load matching can lead to negative $N P V S$ ) and the optimal configuration can be found only with an hourly approach (evaluate at every timestep the energy flows). It is possible to notice from Table 5 that in this case the cumulative methods tend to result in bad design. Some of them (Annual, January, April and October cumulative methods) lead to oversized systems which costs can't be repaid during the supposed lifetime of the plant. With respect to the Italian decree, the hourly optimization (in this case, it depends on the load profile) lead to the installation of 50\% more $P V$ in terms of $\mathrm{kWp}$ causing an increasing of the $23 \%$ of the $N P V$ at the end of the considered lifetime. Also considering fixed tariff regime, the constant load method leads to acceptable results. In conclusion it is possible to say that the tariff regime strongly influences the results; in particular in case of fixed tariff or more complex tariff regime it is possible to find the optimal configuration only using an hourly approach.

Table 5: Fixed tariff

\begin{tabular}{|c|c|c|c|c|c|}
\hline Method & $\begin{array}{c}\text { Size } \\
{[\mathbf{k W p}]}\end{array}$ & $\begin{array}{c}\text { SC } \\
{[\%]}\end{array}$ & $\begin{array}{c}\text { SP } \\
{[\%]}\end{array}$ & $\begin{array}{c}\text { NPV } \\
{[€]}\end{array}$ & $\boldsymbol{P P}$ \\
\hline $\begin{array}{c}\text { D.Lgs. } \\
28 / 2011\end{array}$ & 7.08 & 99.9 & 19.7 & 5581.6 & 12.5 \\
\hline Annual & 35.8 & 45.5 & 44.9 & -15982.5 & $>25$ \\
\hline January & 93.9 & 23.5 & 49.7 & -96911.3 & $>25$ \\
\hline April & 27.3 & 56.0 & 42.2 & -5637.3 & $>25$ \\
\hline July & 17.7 & 73.2 & 37.0 & 3349.4 & 17.7 \\
\hline October & 53.8 & 32.3 & 47.9 & -40048.8 & $>25$ \\
\hline $\begin{array}{c}\text { Hourly } \\
\text { Const. } \\
\text { load }\end{array}$ & 10.6 & 93.6 & 27.7 & 6871.3 & 13.5 \\
\hline
\end{tabular}

\section{PV + EES}

Thanks to the hourly based approach, the new version of ProCasaClima can be used for the design process of an electric storage evaluating at hourly timestep the state of charge of the batteries, the $P V$ production and load consumption. It aims to decrease the risk of oversized or undersized electric storages. Inputs required for designing the storage in the early design phase are accessible from datasheets as capacity, depth of discharge and costs. An example of application is the sizing of a PV + EES. In this case it was decided to maximize the $N P V$ setting a restriction on the minimum percentage of self-produced energy. In that case $S P_{\min }$ was set equal to $60 \%$ and it was assumed net billing as tariff regime. The tool evaluates the consumptions, $P V$ production and battery state necessary for the calculation of the hourly energy flows between the plant, the battery, the user and the grid as shown in Figure 7. In this way, the user can optimize the $P V$ coupled with the storage system. Table 6 reports the results obtained optimizing the battery and the $P V$ capacity using the minimum self-production criteria.

Table 6: PV+EES optimization

\begin{tabular}{|c|c|c|c|}
\hline $\begin{array}{c}\text { Size } \\
{[\mathbf{k W p}]}\end{array}$ & $\begin{array}{c}\text { Battery } \\
{[\mathbf{k W h}]}\end{array}$ & $\begin{array}{c}\text { SC } \\
{[\%]}\end{array}$ & $\begin{array}{c}\text { SP } \\
{[\%]}\end{array}$ \\
\hline 53.6 & 21.0 & 40.1 & 60.0 \\
\hline
\end{tabular}

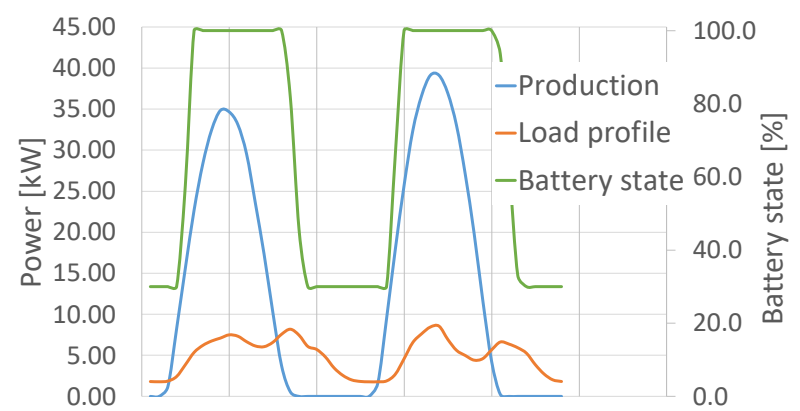

Figure 7: hourly profiles

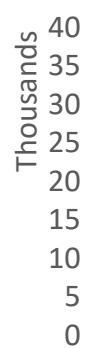

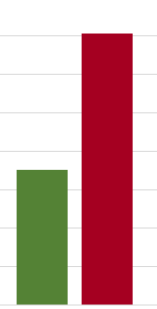
energy [kWh]
Purchased
- Hourly PV+ESS optimization D.Lgs. 28/2011

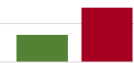

Electricity bills

$[€]$
Figure 8: $P V+E E S$ compared with the Italian decree

Figure 8 shows the comparison between the configuration reported in Table 6 and the one suggested by the Italian decree (method 1). The solution considering the storage system leads to a relevant decreasing of the purchased energy which was reduced by $60 \%$ with respect to the case without $P V$ (for comparison, the solution designed with the annual cumulative method leads to a reduction of $46 \%$ of the purchased energy) with the consequent reduction of the electricity bills. From the economic point of view, the predicted $N P V$ after 25 years is higher with respect to the one obtained with the Italian decree.

\section{Discussion}

The previously shown example demonstrates the importance of using an hourly based approach to obtain a high-quality design of the PV + EES which can lead to optimized systems both from the energy and the economical point of view. As shown in Figure 7, the system with optimized battery and photovoltaic system 
reduces the energy purchased (since we set the minimum $S P$ to $60 \%$ ) maintaining a good value of $N P V$. Of course, reducing the energy taken from the grid can reduce grid costs and balancing issues related to renewable sources and decrease the carbon footprint of the users.

\section{Conclusions}

The paper shows the potential economic benefit associated to the adoption of an hourly based approach from the first phases of the early design process of a photovoltaic system. The method was applied to a specific case of study and compared with different and commonly used design approaches. The maximum potential $N P V$ of the analyzed system was found with the new version of ProCasaClima through the optimization of the system capacity based on hourly energy balances of the real consumption profile. Commonly used monthly based calculations, by lacking a relation between capacity of components and their performance, cannot aid the sizing of $P V$ plants and batteries from the economical point of view (unless net billing is adopted as tariff regime). They can lead to undersized or oversized systems with bad energy KPIs (for example $S C=19 \%$ using the cumulative method based on January). In numerous case studies the actual Italian laws are conservative and can lead to undersized systems with $N P V S$ lower than the possible obtainable. In the analyzed case it leads to an $N P V$ reduced by $76 \%$ in case of net billing and to a $19 \%$ reduction considering fixed tariff. In fact, in the analyzed case it suggests the installation of $7.08 \mathrm{kWp}, 80 \%$ less than the optimal size obtained considering net billing (35.8 kWp). On the contrary, oversized systems (such as those linked with the cumulative demand) can lead to economically unsustainable projects. On the contrary, the new approach takes into account the hourly energy flows between grid, $P V$ plant, load, EES and can support the designers to obtained more sustainable projects. Moreover, it was shown that the method can be applied with good results also when the hourly electrical profile is not available considering a constant demand. Finally, it was demonstrated that adopting an hourly based approach it is possible to predict and increase the self-produced energy and properly design the required battery capacity to achieve the goals of designers from the energy point of view (increasing the $N P V$ by $142 \%$, from $5600 €$ to 13400 $€)$. In conclusion, through the comparison with commonly used design methods it is possible to highlight the importance of adopting hourly based approaches (with known or assumed electrical profile) to improve the quality and sustainability of $P V$ projects.

\section{Acknowledgements}

The authors would like to acknowledge the financial support for this research received through the European Regional Development Fund (ERDF) within the project BuildDOP (project no. FESR1022).

\section{References}

ARERA. (2012, 12 20). Delibera 20 dicembre 2012. 570/2012/R/efr.

DECRETO LEGISLATIVO n. 28. (2011, 3 3). Attuazione della direttiva 2009/28/CE sulla promozione dell'uso dell'energia da fonti rinnovabili, recante modifica e successiva abrogazione delle direttive 2001/77/CE e 2003/30/CE.

Freitas, S., Reinhart, C., \& Brito, M. C. (2018). Minimizing storage needs for large scale photovoltaics in the urban environment. Solar Energy, 375-389.

Lovati, M., Salvalai, G., Fratus, G., Maturi, L., Albatici, R., \& Moser, D. (2018). New method for the early design of BIPV with electric storage: a case study in northern Italy. Sustainable Cities and Society.

Pflugradt, N. (2019). Load profile generator. Tratto da https://www.loadprofilegenerator.de

Thornton, G. (2018). "Renewable Energy Discount Rate Survey Results-2017.". Grant Thornton and Clean Energy Pipeline Initiative, Grant Thornton UK LLP.

Waibel, C., Mavromatidis, G., Bollinger, A., Evins, R., \& Carmeliet, J. (2018). Sensitivity analysis on optimal placement of façade based photovoltaics. Proceedings of the ECOS.

Yusoff, N. F. (2016). "Operating Temperature of Photovoltaic Module for Retrofitted GridConnected Photovoltaic System on Metal Roof.". International Journal of Simulation: Systems, Science and Technology, 54-1. 